Brit. Heart F., 1966, 28, 409.

\title{
Effect of Atropine on Bradycardia and Hypotension in Acute Myocardial Infarction
}

\author{
MICHAEL THOMAS AND DONALD WOODGATE* \\ From the Medical Research Council Cardiovascular Research Group, Department of Medicine, Postgraduate Medical \\ School of London, W. 12, and St. Andrew's Hospital, Billericay, Essex
}

Bradycardia in patients with acute myocardial infarction has received little attention until recently (Haden et al., 1963), though rapid heart rate has long been recognized as a clinical feature of some of the most seriously ill patients. Using continuous electrocardiographic monitoring, Brown et al. (1963) found that of 29 patients whose electrocardiogram was recorded up to the time of death, 11 showed progressive slowing of the heart with the development of a "lower" pacemaker. Billings et al. (1949) had previously reported that a low heart rate in patients with acute myocardial infarction was associated with a high mortality.

During serial clinical and hæmodynamic study of patients in an intensive care unit (Shillingford and Thomas, 1964) and in patients admitted to St. Andrew's Hospital, Billericay, the syndrome of slowing of the heart and falling arterial blood pressure following myocardial infarction has been noted on several occasions. In the most pronounced form the clinical features resembled those of a vasovagal faint. Atropine was found to be effective in raising the heart rate and arterial blood pressure, and in some patients this was associated with general clinical improvement.

The purpose of this paper is to describe some effects of atropine in patients with acute myocardial infarction, to report hæmodynamic data, and to discuss the use of the drug in therapy.

\section{SUBJECTS}

Six patients with acute myocardial infarction were selected to illustrate the effects of atropine on bradycardia and hypotension. Three male patients with unequivocal clinical evidence of acute myocardial infarction, and one patient in whom the diagnosis was

Received September 22, 1965.

*Present address: The Royal Free Hospital, London W.C.1. probable, were studied in the Intensive Coronary Care Unit of Hammersmith Hospital. One female and 2 male patients with acute myocardial infarction were treated at St. Andrew's Hospital, Billericay, Essex. The ages of the patients ranged from 49 to 72 years.

Arterial pressures were measured via a polythene catheter ${ }^{\star}$ introduced percutaneously by the Seldinger method into a brachial artery using local anæsthesia. The tip of the arterial catheter lay $10 \mathrm{~cm}$. from the point of insertion. Pressures were measured with a Statham P23Gb strain gauge, and a direct writing recorder (Devices Ltd.) was used. Pressures were measured with reference to a point $5 \mathrm{~cm}$. below the sternal angle.

Cardiac output was measured by an indicator dilution technique using a photoelectric earpiece (Cambridge Instrument Co.) and Coomassie Blue dye (I.C.I.) as indicator.

\section{RESULTS}

Patient 1. A 62-year-old man. This patient was admitted with a history of retrosternal chest pain radiating to the left arm, associated with nausea and faintness which had been present for several hours. A similar episode three years previously had been treated with six weeks' bed-rest, since which time he had suffered from periods of aching chest pain provoked by walking and relieved by rest.

When admitted he looked ill, pale, and frightened. Heart rate was 60 a minute, blood pressure was $120 / 90$ $\mathrm{mm}$. Hg. Jugular venous pressure and heart sounds were normal. The cardiogram showed pathological $Q$ waves, $S-T$ segment elevation, and $T$ wave inversion in leads II, III, and aVF. He was in sinus rhythm.

During the first 8 hours of admission, heart rate increased to 105 a minute. Blood pressure remained of the same order $(115 / 80 \mathrm{~mm}$. $\mathrm{Hg})$. During the subsequent five hours heart rate and systolic blood pressure fell progressively to 50 a minute and $50 \mathrm{~mm}$. $\mathrm{Hg}$, respectively. He looked pale and his extremities became cold. Chest pain returned. Intermittent injections of metaraminol $5 \mathrm{mg}$. intramuscularly increased systolic

$\star$ PE60 Intramedic U.S.A. 
blood pressure to $60-80 \mathrm{~mm}$. $\mathrm{Hg}$, but general deterioration continued. He was then given atropine sulphate $0.6 \mathrm{mg}$. intravenously and $0.6 \mathrm{mg}$. intramuscularly. Heart rate rose immediately to 110 a minute, and the blood pressure to $120 / 80 \mathrm{~mm}$. Hg. Sinus rhythm was present at all times. He improved generally, and was afterwards maintained on atropine sulphate $1.2 \mathrm{mg}$. intramuscularly every 6 hours for 4 days, during which time heart rate remained in the range $90-100$ a minute and blood pressure of the order of $100 / 60 \mathrm{~mm}$. Hg. He complained of a dry mouth and later of visual hallucinations, after which the drug was withdrawn without ill effect.

Further progress was uneventful and he left hospital 4 weeks after admission; 6 weeks later he was seen to be well and free from symptoms.

Patient 2. A 70-year-old woman. This patient was admitted following two hours severe chest pain which began soon after some unusual exertion. Previous to this she had been treated with thyroid extract for 12 years following the diagnosis of myxœdema, but had had no symptoms of ischæmic heart disease.

On admission she looked ill, pale, and cyanosed. She was retching and confused. Heart rate was 40 a minute, blood pressure was $50 / 20 \mathrm{~mm}$. Hg. Jugular venous pressure was raised. Heart sounds were faint. The cardiogram showed pathological $Q$ waves, $S-T$ segment elevation, and $T$ wave inversion in leads II, III, aVF, and V4-V6. No $P$ waves were visible.

Systolic blood pressure rose to $80 \mathrm{~mm}$. $\mathrm{Hg}$ following intramuscular injection of metaraminol $5 \mathrm{mg}$. and hydrocortisone $100 \mathrm{mg}$., but her general condition did not improve and the bradycardia remained. An intravenous injection of atropine sulphate $1.2 \mathrm{mg}$. was then given, within a minute of which the heart rate increased to 80 a minute and later to 100 a minute. Blood pressure increased rapidly to $140 / 80 \mathrm{~mm}$. $\mathrm{Hg}$ and later to $190 / 110$ $\mathrm{mm}$. Hg. Her skin became pink and her extremities became warmer to palpation. She remained confused for 24 hours. Further treatment consisted of continuous oxygen and small doses $(50 \mathrm{mg}$. intramuscularly or $10 \mathrm{mg}$. intravenously) of pethilorfan for pain. An injection of atropine sulphate $1.2 \mathrm{mg}$. intramuscularly was given on the third day when the heart rate fell to less than 50 a minute. After this episode heart rate and blood pressure were stable at $60-80$ a minute and $130 / 90$ $\mathrm{mm} . \mathrm{Hg}$, respectively.

Progress thereafter was uneventful and the patient left hospital four weeks after admission. Four weeks after discharge she was seen to have made a good recovery without residual symptoms; the only treatment being thyroid extract, which was continued after the acute illness.

Patient 3. A 72-year-old man. This patient was admitted in extremis. A history of chest pain had been elicited by his doctor. On admission he was seen to be pale, cyanosed, and breathless. Heart rate was 80 a minute, in sinus rhythm; systolic blood pressure was $100 \mathrm{~mm}$. Hg. Jugular venous pressure was raised. Heart sounds were inaudible. Crepitations and rhonchi were heard in all areas in the chest. The cardiogram showed the changes of a recent posterior myocardial infarction. Chest radiograph showed cardiac enlargement with pulmonary venous distension and pulmonary œdema. Blood urea was $115 \mathrm{mg} . / 100 \mathrm{ml}$. He was treated with oxygen, digoxin, frusemide, and tetracycline.

Sixteen hours later his condition deteriorated rapidly and he became very pale and unconscious. Heart rate was 30 a minute; systolic blood pressure was $40 \mathrm{~mm}$. Hg. Atropine sulphate $1.2 \mathrm{mg}$. was injected intravenously, following which the heart rate increased to 100 a minute, blood pressure increased to $130 / 90 \mathrm{~mm}$. $\mathrm{Hg}$, and the patient regained consciousness. An intramuscular injection of metaraminol $5 \mathrm{mg}$. was then given. Subsequent to this initial improvement, the patient's general condition remained poor, pulmonary œedema persisted, and he died three hours later. Permission for necropsy was not obtained.

Patient 4. A 49-year-old man. This patient was well until admitted to hospital following a sudden crushing pain across the front of his chest associated with faintness and vomiting. When admitted his general condition was good. Heart rate 80 a minute, regular; blood pressure was $160 / 85 \mathrm{~mm}$. Hg. Jugular venous pressure was normal. An atrial sound was present. Electrocardiogram showed pathological $Q$ waves and inverted $\mathrm{T}$ waves in leads II, III, and aVF. During the next 18 hours progress was uneventful but the chest pain recurred on the second day.

During the second day there were several periods of hypotension in which the systolic blood pressure fell from 140 to $100 \mathrm{~mm} . \mathrm{Hg}$, and the pulse slowed from 80 to 45 a minute. Isoprenaline $0.05 \mathrm{mg}$. was given during one of these episodes and the heart rate and blood pressure returned to previous levels. Sinus rhythm was present at all times.

Bradycardia returned over the course of three hours and the heart rate fell to 34 beats a minute. During this particular episode the $P$ wave in lead II became inverted and the P-R interval shortened to 0.06 second. Systolic blood pressure again fell to less than $100 \mathrm{~mm}$. Hg. Elevation of the foot of the bed and administration of $\mathrm{O}_{2}$ was followed by a transient increase in heart rate to 55 a minute. An injection of $0.6 \mathrm{mg}$. atropine sulphate intravenously over 6 minutes was followed by an increase in heart rate from 55 to 110 a minute and of blood pressure to $150 \mathrm{~mm}$. $\mathrm{Hg}$ (Fig. 1). The P-R interval lengthened and the $P$ wave became upright (Fig. 2).

The patient's clinical state improved in that the blood pressure and heart rate showed no further tendency to fall and the sinus pacemaker remained dominant. He made an uninterrupted recovery and returned to fulltime employment.

Patient 5. A65-year-old man. This patient had two myocardial infarctions, one 5 years and the other 10 months before admission. Three hours before admission he had an episode of severe chest pain followed by general malaise. When admitted he looked ill but was not pale or sweating and was free from pain. Rectal temperature was $102^{\circ} \mathrm{F}$. $\left(39^{\circ} \mathrm{C}\right.$.) Heart rate was 66 


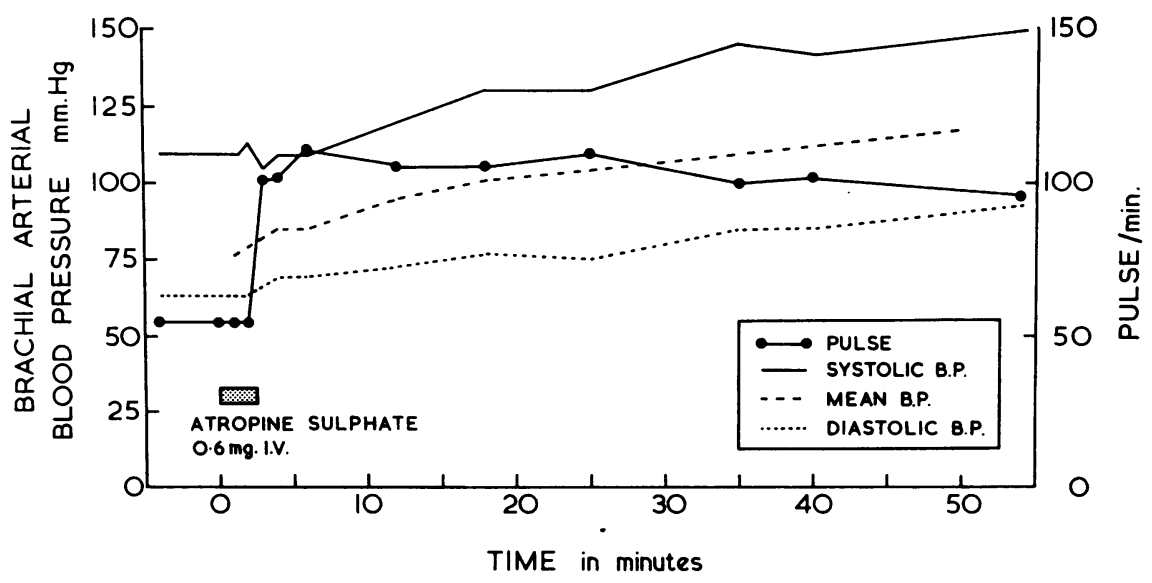

FIG. 1.-Patient 4: diagram showing the changes in pulse rate and brachial arterial pressure following the injection of $0.6 \mathrm{mg}$. atropine sulphate.

a minute, regular. Blood pressure was $80 / 40 \mathrm{~mm}$. $\mathrm{Hg}$. Jugular venous pressure was $+3 \mathrm{~cm}$. The apex beat was palpable 1 in. $(2.5 \mathrm{~cm}$.) outside the mid-clavicular line. A third heart sound was present. Fine crepitations were audible at the bases of the lungs. The cardiogram showed a pathological $Q$ wave and $T$ wave inversion in lead III, $\mathrm{T}$ wave inversion in leads II and

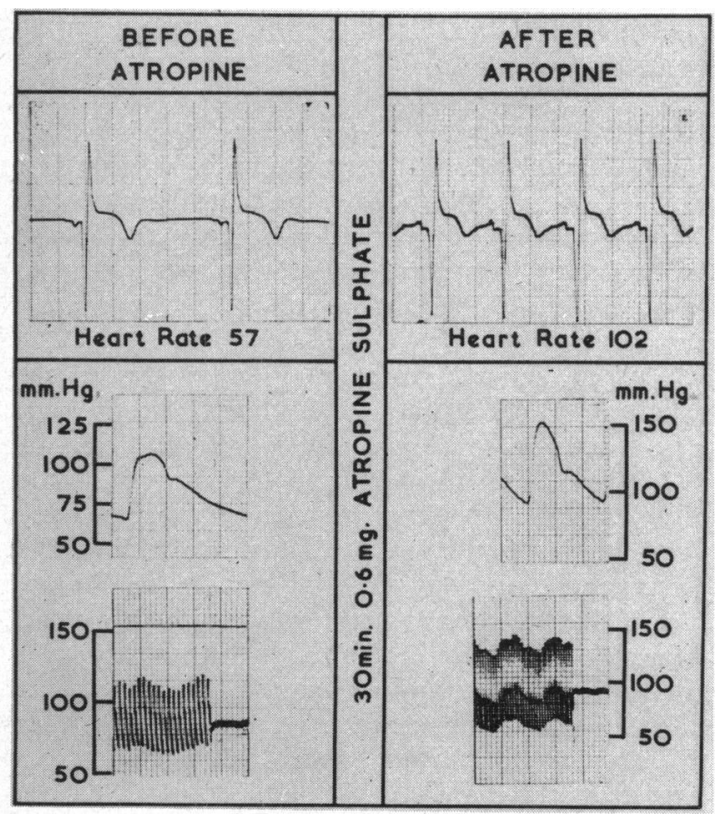

Fig. 2.-Patient 4: Electrocardiogram and brachial arterial pressure traces before and after the administration of $0.6 \mathrm{mg}$. atropine sulphate. The inverted $P$ wave became upright and the $P-R$ interval lengthened. Heart rate rose from 57 a minute to 102 a minute, and systolic blood pressure from $109 \mathrm{~mm}$. $\mathrm{Hg}$ to $150 \mathrm{~mm}$. $\mathrm{Hg}$.
aVF, an intraventricular conduction defect, and changes due to digitalis. At the time of admission the blood urea was $51 \mathrm{mg} . / 100 \mathrm{ml}$. and the serum potassium was $4.5 \mathrm{mEq} / \mathrm{l}$.

Soon after admission the blood pressure rose spontaneously to $90 / 60 \mathrm{~mm}$. Hg. During the next 24 hours an episode of dyspncea occurred but this responded to morphine $10 \mathrm{mg}$. and later to aminophylline $250 \mathrm{mg}$. His cardiovascular state remained unchanged for 4 days and there was oliguria. The blood urea increased to $185 \mathrm{mg} . / 100 \mathrm{ml}$.; serum potassium to $5.5 \mathrm{mEq} / \mathrm{l}$. Peritoneal dialysis was undertaken. On the fourth hospital day sinus rhythm changed to nodal rhythm at a rate of 48 a minute and systolic blood pressure fell to $60 \mathrm{~mm}$. $\mathrm{Hg}$. The foot of the bed was raised 9 in. $(23 \mathrm{~cm}$.). Following an injection of atropine sulphate $0.6 \mathrm{mg}$. intravenously, the heart rate rose to 65 a minute and the blood pressure to $95 / 65 \mathrm{~mm}$. $\mathrm{Hg}$. The rise in heart rate and blood pressure was associated with a temporary return to normal sinus rhythm. The rhythm was unstable, but recurrence of nodal rhythm was successfully treated with further doses of atropine. On the sixth hospital day dialysis was discontinued. $\mathrm{He}$ gradually improved generally with increase in urine volume and continued fall in blood urea, but died suddenly on the tenth hospital day. Permission for necropsy was not obtained.

Patient 6. A 53-year-old man. This patient was admitted following an attack of retrosternal chest pain radiating to the left upper arm. This was associated with a dizzy sensation and sweating. For 18 months before this episode he had had occasional central chest pain accompanied by sweating. Following one prolonged period of chest pain he had spent six weeks in another hospital, but there was no cardiographic evidence of myocardial infarction at this time.

On admission his general condition was good. Heart rate was 60 a minute; blood pressure was $150 / 90 \mathrm{~mm}$. Hg. Jugular venous pressure was normal. Heart 


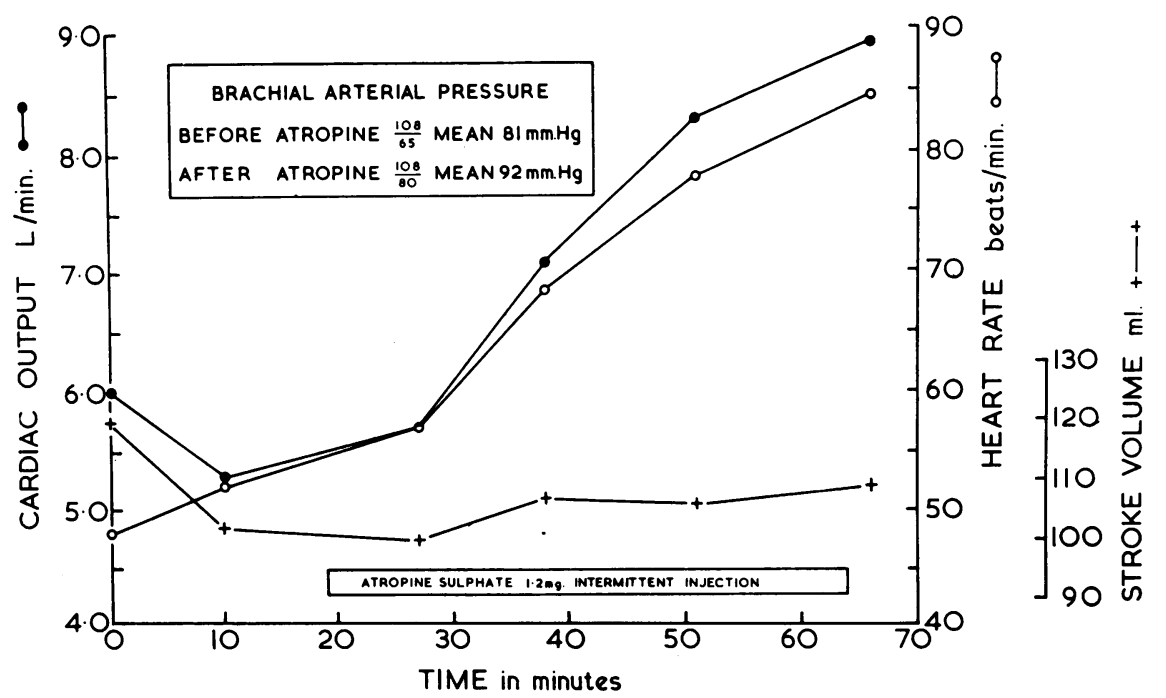

FIG. 3.-Patient 6: diagram showing the progressive increase in cardiac output which occurred in association with the increase in heart rate when atropine sulphate was injected intermittently. Stroke volume showed little change. Mean brachial arterial pressure rose.

sounds were normal with an ejection type systolic murmur. The cardiogram did not show evidence of acute myocardial infarction.

Nine hours after admission he felt generally unwell and began to sweat but there was no pain. The blood pressure fell to $90 / 50 \mathrm{~mm}$. $\mathrm{Hg}$, and this was associated with a fall in heart rate to 46 a minute. At this time the cardiogram showed a P-R interval of $0.24 \mathrm{sec}$. but no evidence of infarction. An injection of atropine sulphate $0.6 \mathrm{mg}$. was given, after which the heart rate increased to the normal range.

During the next 24 hours the heart rate was low, at times falling to 40 a minute. Systolic blood pressure was in the range $90-100 \mathrm{~mm} . \mathrm{Hg}$. The patient's general condition remained fair. Measurements of arterial pressure, heart rate, and cardiac output were made before and during the intermittent intravenous injection of small doses of atropine sulphate (Fig. 3).

Heart rate increased progressively from a range of 45-55 to 80-90 a minute. Associated with this was an increase of cardiac output from approximately $5 \cdot 51 . / \mathrm{min}$. to almost $9 \mathrm{l} . / \mathrm{min}$. The stroke volume showed little change. Mean brachial arterial pressure increased from 81 to $92 \mathrm{~mm}$. $\mathrm{Hg}$, while the systolic pressure remained constant at $108 \mathrm{~mm}$. $\mathrm{Hg}$.

During the hospital admission the heart rate was often in the range of 50-60 a minute, and the $P-R$ interval failed to return to normal. When later seen at an outpatient visit, the heart rate was 60 a minute, and the blood pressure was $130 / 80 \mathrm{~mm}$. Hg. He occasionally experiences a retrosternal chest pain radiating to the left arm, but is generally well.

\section{Discussion}

It is well recognized that tachycardias in patients with acute myocardial infarction can be directly responsible for a fall in arterial blood pressure with general deterioration in the patient's condition. Slowing of the heart, its significance, and clinical management have received little attention.

Continuous electrocardiographic monitoring of patients with acute myocardial infarction (Brown et al., 1963) has shown that in a high proportion of patients dying suddenly, the heart rate is slow and the $P-R$ interval short at the time of death. The exact relation between the electrocardiographic and clinical changes could not be seen from the data available, and whether bradycardia was a primary or secondary change during circulatory collapse is not clear.

The cardiac response to systemic hypotension usually involves an increase in heart rate probably initiated by carotid and aortic reflexes. Failure to increase heart rate or a fall in heart rate under these circumstances implies a significant disturbance in circulatory homeostasis. Hæmodynamic studies (Thomas, Malmcrona, and Shillingford, 1965) have shown that in some patients with acute myocardial infarction heart rate may be slow in the presence of low cardiac output and low arterial blood pressure.

The possible mechanisms responsible for defective heart rate regulation are several, including local arterial disease in pacemaker tissue or local ischæmia due to low arterial perfusion pressure. It may be significant that a high proportion of our patients with the bradycardia syndrome had posterior infarctions. Other factors that may prove important are poor perfusion of brain-stem reflex centres (Anrep and Segall, 1926) or the activity of 
primary cardiac reflexes. Reflexes initiated by left ventricular receptors are known to produce bradycardia and vasodilatation when veratrine is introduced into the dog's coronary circulation (Dawes, 1947). Recently such reflex activity has been shown to occur during myocardial ischæmia in dogs (Costantin, 1963). Direct evidence relating to the importance of these reflexes during bradycardia and hypotension in patients with acute myocardial hypotension is not available, and at the present time treatment of the low heart rate low blood pressure syndrome is empirical.

The use of drugs in the treatment of hypotension following acute myocardial infarction has been largely limited to the sympathomimetic amine group, the pressor effect depending on myocardial stimulation and a peripheral vasoconstrictor action. Atropine has been mentioned as beneficial in treating bradycardia in acute myocardial infarction (Agress and Binder, 1957), but measurements of the circulatory consequences are not recorded. We have found atropine to be effective in raising heart rate and arterial blood pressure in circumstances where these have been consistently low or have fallen acutely. When falling heart rate is associated with falling arterial pressure, atropine should be injected slowly by the intravenous route (dose $0.3-2.0 \mathrm{mg}$.) over several minutes, when it is often possible to increase the heart rate progressively to $80-90$ a minute (Fig. 3). The effect of the drug usually lasts 2-4 hours when the injection may be repeated if the tendency to bradycardia and hypotension returns.

The explanation of the beneficial action is difficult without more complete information, but some speculation may be useful. It is possible that reduction in vagal influence on the heart is associated with increased sympathetic bias. An increase in heart rate with increased atrial and ventricular contractile force could result from this. Whether atropine is important in blocking excessive vagal tone produced by primary cardiac or other reflex activity is uncertain. It is unlikely that atropine increases arterial blood pressure by a direct effect on peripheral blood vessels; vasoconstrictor effects of atropine have not been documented at the present time.

\section{SUMMARY}

The syndrome of bradycardia and hypotension has been observed in patients with acute myocardial infarction. Examples with sinus bradycardia, low pacemaker, and nodal rhythm were seen. Treatment with atropine injected intravenously resulted in an increase in heart rate and arterial blood pressure, associated with obvious general clinical improvement in some patients. The possible significance of the syndrome and the use of atropine in its treatment are discussed.

The authors wish to thank Dr. J. P. Shillingford and Dr. J. W. Fawcett for permission to report these observations made in patients under their care. They are also indebted to Mr. Peter Burgess and Miss Diana Cuttriss for technical assistance. Miss Jean Powell drew the diagrams.

\section{REFERENCES}

Agress, C. M., and Binder, M. J. (1957). Cardiogenic shock. Amer. Heart f., 54, 458.

Anrep, G. V., and Segall, H. N. (1926). The central and reflex regulation of the heart rate. F. Physiol. (Lond.), 61, 215.

Billings, F. T., Kalstone, B. M., Spencer, J. L., Ball, C. O. T. and Meneely, G. R. (1949). Prognosis of acute myocardial infarction. Amer. F. Med., 7, 356.

Brown, K. W. G., MacMillan, R. L., Forbath, N., Mel'Grano, F., and Scott, J. W. (1963). Coronary unit. An intensive-care centre for acute myocardial infarction. Lancet, 2, 349.

Costantin, L. (1963). Extracardiac factors contributing to hypotension during coronary occlusion. Amer. $\mathcal{f}$. Cardiol., 11, 205.

Dawes, G. S. (1947). Studies on veratrum alkaloids. VII. Receptor areas in the coronary arteries and elsewhere as revealed by the use of veratridine. F. Pharmacol. exp. Ther., 89, 325.

Haden, R. F., Langsioen, P. H., Rapoport, M. I., and McNerney, J. J. (1963). The significance of sinus bradycardia in acute myocardial infarction. Dis. Chest, 44, 168.

Shillingford, J. P., and Thomas, M. (1964). Organisation of unit for intensive care and investigation of patients with acute myocardial infarction. Lancet, 2, 1113.

Thomas, M., Malmcrona, R., and Shillingford, J. (1965). Hemodynamic changes in patients with acute myocardial infarction. Circulation, 31, 811. 